\title{
Primary Aortodigestive
}

Fistula: A Rare and Potentially

Lethal Cause of Gastrointestinal

Hemorrhage

\author{
Saskia Ditisheim Marc Girardin Jean-Marc Dumonceau \\ Antoine Hadengue Jean Louis Frossard \\ Department of Gastroenterology and Hepatology, University Hospital of Geneva, \\ Geneva, Switzerland
}

\section{Key Words}

Aortodigestive fistula - Primary aortodigestive fistula - Rare endoscopic findings .

Gastrointestinal hemorrhage · Duodenum · Endoscopy

\begin{abstract}
Primary aortodigestive fistulas (PAFs) are a rare cause of gastrointestinal bleeding, with an incidence of $0.04-0.07 \%$ in autopsy series. The diagnosis of PAF is difficult and should be considered in patients with gastrointestinal hemorrhage of obscure origin. Because of its high mortality rate, clinical recognition of prodromal symptoms for early diagnosis is crucial for effective treatment. We report on the case of a 79-year-old patient with a PAF who was admitted for hematochezia and melena. The PAF was suspected during upper gastrointestinal endoscopy and confirmed by CT angiography.
\end{abstract}

\section{Introduction}

The diagnosis of primary aortodigestive fistulas (PAFs) is often difficult and should always be considered in elderly patients with gastrointestinal bleeding. Whereas PAFs are a rare and often fatal cause of gastrointestinal hemorrhage $[1,2]$, secondary aortodigestive fistulas are uncommon but very important complications of previous abdominal aortic reconstructions that can occur months to years after aortic surgery $[3,4]$. In the primary form, fistulas are nearly always associated with abdominal aortic aneurysm that causes progressive erosion of the bowel wall and finally blood irruption into the gut lumen. In both primary and secondary aortodigestive fistulas, the clinical manifestation is always upper gastrointestinal bleeding [3]. A high index of clinical suspicion combined with 
rapid imaging is required because a favorable outcome exclusively relies on prompt radiological or surgical management.

We report on the case of a PAF that was suspected during upper gastrointestinal endoscopy performed in a patient presenting with melena and hematochezia.

\section{Case Report}

A 79-year-old patient was admitted for melena and hematochezia that had started several days before admission without any abdominal pain. His previous medical history included hypertension treated by beta blockers. He was an active smoker (one pack per day, 40 pack years), but otherwise in good health. His current medication consisted of aspirin $100 \mathrm{mg}$ daily and atenolol.

The patient was admitted to the emergency department due to general weakness. At admission, blood pressure was low $(85 / 65 \mathrm{~mm} \mathrm{Hg})$, heart rate was 80 per minute and hemoglobin was $122 \mathrm{~g} / \mathrm{l}$. Blood pressure rose to $110 / 70 \mathrm{~mm} \mathrm{Hg}$ after infusion of 1 liter of normal saline and remained stable overnight with hemoglobin at $110 \mathrm{~g} / \mathrm{l}$ and no further clinical signs of ongoing gastrointestinal bleeding. Suddenly, $24 \mathrm{~h}$ after admission, significant hematochezia started with transient hypotension and tachycardia, from which the patient recovered spontaneously. Based on his current condition, the first postulated diagnosis was colonic diverticular hemorrhage. A colonoscopy was performed and showed fresh blood in the right colonic angle and more blood coming upstream to this area, suggesting that the source of bleeding was located in the upper part of the intestinal tract. Therefore upper gastrointestinal endoscopy was immediately performed. No blood was found in the upper digestive tract, but in the third portion of the duodenum a small lesion with a black edge suggestive of a small crater-like perforation without any sign of active hemorrhage was found (fig. 1). A CT angiography scan showed an infrarenal aortic aneurysm with air inside the aneurysm (fig. 2 ). The patient underwent immediate surgery for aortic repair using graft prosthesis and patch on the duodenal fistula opening.

Postoperative evolution was favorable and the patient was discharged from hospital at day 28. Forty days after initial surgery the patient was readmitted for a new episode of melena. Upper gastrointestinal endoscopy was performed and showed a pulsatile bleeding in the third part of the duodenum that was clipped endoscopically (fig. 3). A CT angiography scan revealed a periprosthetic collection with air and a likely recurrence of the aortoduodenal fistula without extravasation of contrast agent from the vascular lumen. The patient underwent a second laparotomy; the periprosthetic collection corresponded to an abscess and was drained. Macroscopically, the initial duodenal patch was intact and a new duodenal perforation was found $4 \mathrm{~mm}$ above the duodenal patch. The site of the duodenal perforation was in contact with the periprosthetic abscess. The visceral surgeon decided for a duodenojejunectomy with a duodenojejunal end-to-end anastomosis. After an initial good recovery from surgery, the patient suffered a cardiac arrest with electromechanic dissociation on day 8 and deceased after unsuccessful resuscitation. The cause of death was a rupture of the aortic prosthesis as revealed by autopsy.

\section{Discussion}

The incidence of PAFs has been reported to vary between 0.04 and $0.07 \%$ in large autopsy series $[1,5,6]$. Sixty to eighty-five percent of all PAFs complicate aortic aneurysms that result from atherosclerosis [5]. Fistulas between vessels and the digestive tract can also occur in other contexts (tumors, infections, foreign bodies, radiation, ...) but are less frequent [5]. Secondary vascular-enteric fistulas are far more frequent than primary fistulas (incidence $0.5-2.3 \%$ ) and are due to previously implanted vascular prostheses [6].

As mentioned above, the diagnosis of a PAF is difficult and should be considered in patients with gastrointestinal hemorrhage of obscure origin. The classical presentation including the triad of gastrointestinal hemorrhage, abdominal pain and pulsatile mass is 
not always present. In fact this clinical presentation occurs in less than $25 \%$ of cases [7]. However, this diagnosis must be suspected when a patient known for an aortic aneurysm presents with gastrointestinal bleeding. The most frequent clinical presentation consists in prodromal slight gastrointestinal bleeding that precedes massive hemorrhage and exsanguination. Intermittent herald bleeding can occur when a thrombus closes temporarily the fistula as described here. Upper gastrointestinal endoscopy can be useful to exclude other potential causes of gastrointestinal bleeding and can also reveal blood in the duodenum coming from an extrinsic pulsatile mass. Endoscopic findings such as the opening of the fistula is exceptionally rare. CT angiography scan is best suited for detection of arteriovisceral fistulas despite its variable sensitivity and specificity [8]. Ectopic air close to or in the aorta is the predominant CT finding in PAF. Even if not routinely performed, abdominal ultrasonography may be useful in unstable patients or when contrast agents are contraindicated. Angiography defines individual vascular anatomy and is useful for surgical planning of aortic reconstruction. Standard treatment includes surgical repair of the aortic aneurysm and fistula correction.

With appropriate treatment variable survival rates have been reported in the literature, ranging from 18 to 93\% [6]. In cases of PAF from aortic aneurysm and no evidence of infection, aortic repair with graft, coupled with repair of the duodenum and placement of omentum between intestinal and vessel repair is a good option [6]. Indeed, in situ graft aortic replacement can be considered if the level of contamination is mild [6]. If PAF remains untreated, the mortality rate is up to $100 \%$.

\section{Conclusions}

PAF is a rare complication of aortic aneurysms and a rare cause of gastrointestinal bleeding. However, because of its high mortality rate, it must be suspected in patients known to have an aortic aneurysm. Clinical recognition of prodromal symptoms for early diagnosis is crucial for rapid and effective treatment. Recognition of the prodromal bleed of a PAF prior to massive hemorrhage is difficult and can be unspecific. However, important hematochezia concomitantly associated with hemodynamic instability, as featured in our case, is suggestive of an ongoing PAF. Upper gastrointestinal endoscopy and CT angiography are essential for diagnosis. 


\begin{tabular}{r|l|l|l}
$\begin{array}{c}\text { Case Reports in } \\
\text { Gastroenterology }\end{array}$ & $\begin{array}{l}\text { Case Rep Gastroenterol 2011;5:428-432 } \\
\text { DOl: 10.1159/000329881 }\end{array}$ & $\begin{array}{l}\text { Published online: } \\
\text { August 18, 2011 }\end{array}$ & $\begin{array}{l}\text { O 2 2011 S. Karger AG, Basel } \\
\text { ISSN 162--0631 } \\
\text { www.karger.com/crg }\end{array}$ \\
\hline
\end{tabular}

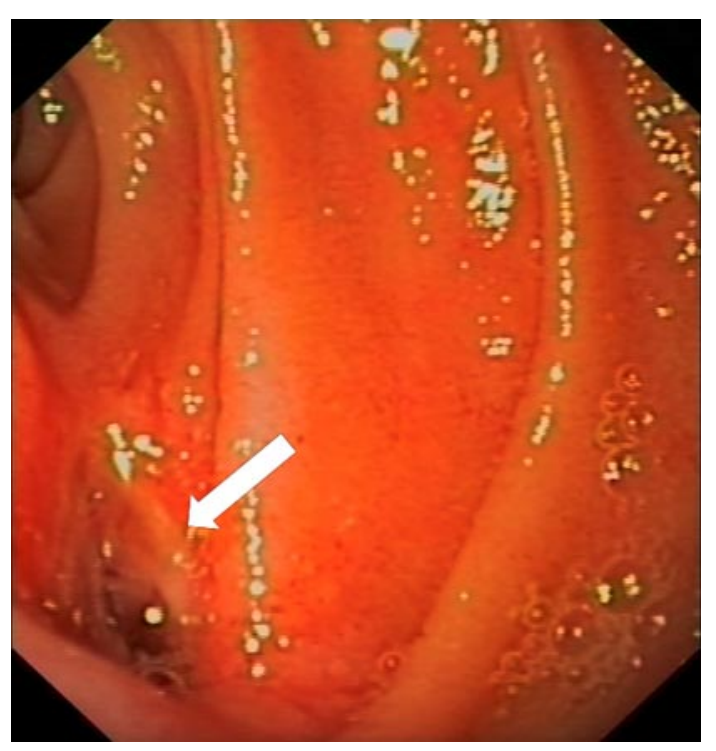

Fig. 1. Endoscopic image of the duodenum. View of an orifice of the PAF in the form of a crater-like perforation.

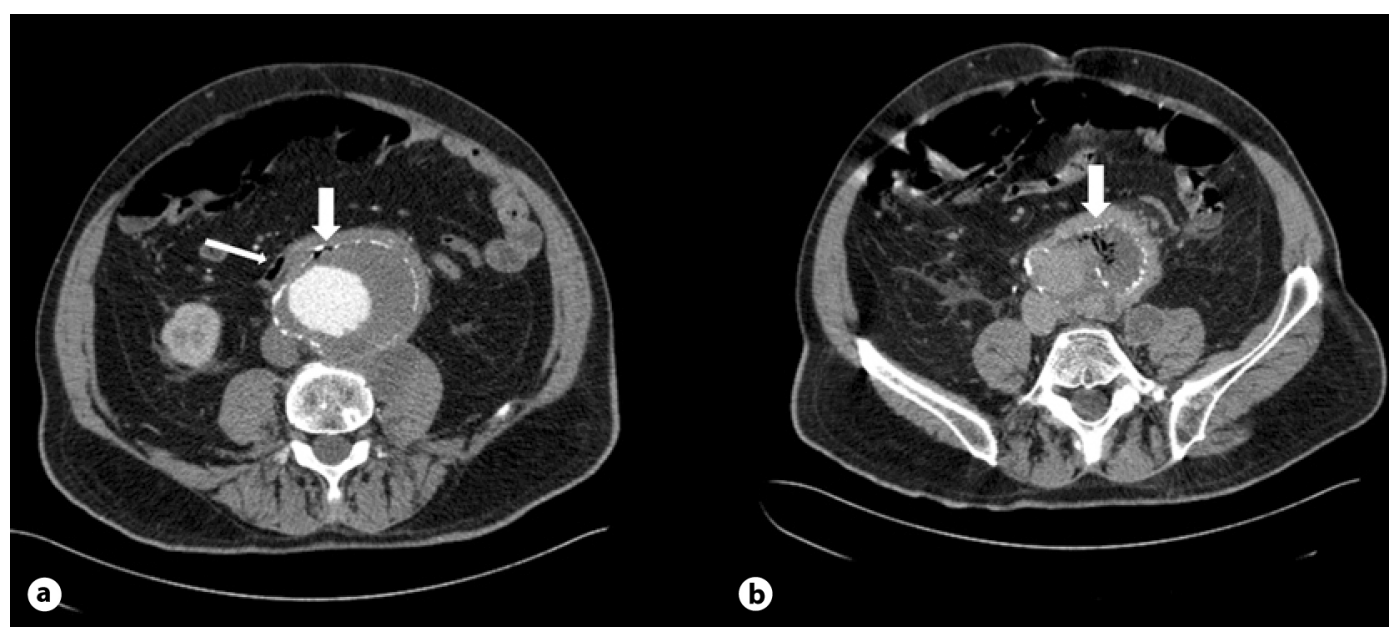

Fig. 2. CT angiography. a, b Ruptured and partially thrombosed aortic aneurysm with air inside the aneurysm lumen (big arrows) and adjacent duodenum (small arrow). 


\begin{tabular}{|c|c|c|c|}
\hline $\begin{array}{r}\text { Case Reports in } \\
\text { Gastroenterology }\end{array}$ & $\begin{array}{l}\text { Case Rep Gastroenterol 2011;5:428-432 } \\
\text { DOI: } 10.1159 / 000329881\end{array}$ & $\begin{array}{l}\text { Published online: } \\
\text { August 18, } 2011\end{array}$ & $\begin{array}{l}\text { (c) } 2011 \text { S. Karger AG, Basel } \\
\text { ISSN } 1662-0631 \\
\text { www.karger.com/crg }\end{array}$ \\
\hline
\end{tabular}

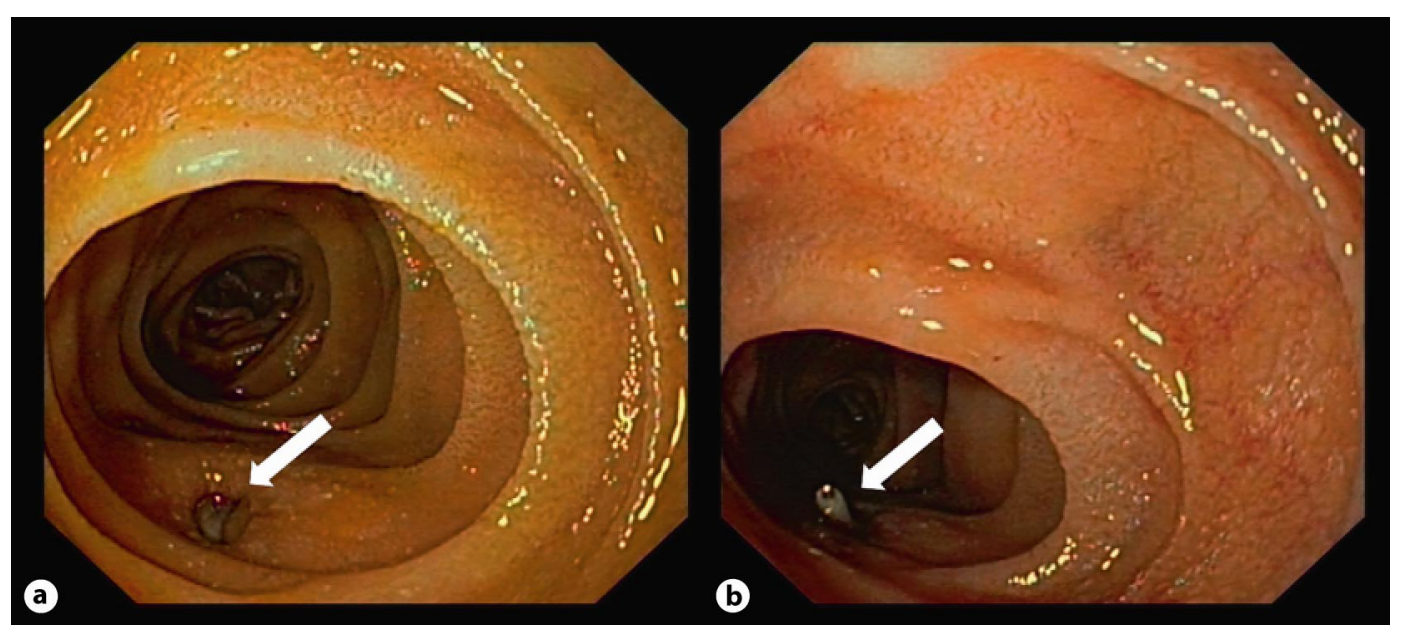

Fig. 3. Endoscopic image of the duodenum. a View of a secondary duodenal fistula (arrow) due to postoperative graft infection. $\mathbf{b}$ View after clipping.

\section{References}

1 Lozano FS, Munoz-Bellvis L, San Norberto E, et al: Primary aortoduodenal fistula: new case reports and a review of the literature. J Gastrointest Surg 2008;12:1561-1565.

-2 Sweeney MS, Gadacz TR: Primary aortoduodenal fistula: manifestation, diagnosis, and treatment. Surgery 1984;96:492-497.

-3 Saratzis N, Saratzis A, Melas N, et al: Aortoduodenal fistulas after endovascular stent-graft repair of abdominal aortic aneurysms: single-center experience and review of the literature. J Endovasc Ther 2008;15:441-448.

4 Bergqvist D, Bjorck M, Nyman R: Secondary aortoenteric fistula after endovascular aortic interventions: a systematic literature review. J Vasc Interv Radiol 2008;19:163-165.

5 Voorhoeve R, Moll FL, de Letter JA, et al: Primary aortoenteric fistula: report of eight new cases and review of the literature. Ann Vasc Surg 1996;10:40-48.

6 Lemos DW, Raffetto JD, Moore TC, et al: Primary aortoduodenal fistula: a case report and review of the literature. J Vasc Surg 2003;37:686-689.

7 Delgado J, Jotkowitz AB, Delgado B, et al: Primary aortoduodenal fistula: Pitfalls and success in the endoscopic diagnosis. Eur J Intern Med 2005;16:363-365.

8 Vu QD, Menias CO, Bhalla S, et al: Aortoenteric fistulas: CT features and potential mimics. Radiographics 2009;29:197-209. 